This item was submitted to Loughborough's Research Repository by the author.

Items in Figshare are protected by copyright, with all rights reserved, unless otherwise indicated.

High resolution 3D chemical characterisation of a cadmium telluride solar cell by dynamic SIMS

PLEASE CITE THE PUBLISHED VERSION

https://doi.org/10.1109/PVSC.2017.8366788

PUBLISHER

(C) IEEE

VERSION

AM (Accepted Manuscript)

LICENCE

CC BY-NC-ND 4.0

REPOSITORY RECORD

Fiducia, Thomas, Kexue Li, Chris R.M. Grovenor, Kurt L. Barth, Walajabad S. Sampath, and Michael Walls. 2019. "High Resolution 3D Chemical Characterisation of a Cadmium Telluride Solar Cell by Dynamic SIMS". figshare. https://hdl.handle.net/2134/33494. 


\title{
High Resolution 3D Chemical Characterisation of a Cadmium Telluride Solar Cell by Dynamic SIMS
}

\author{
Thomas Fiducia ${ }^{1}$, Kexue Li $^{2}$, Chris Grovenor ${ }^{2}$, Kurt Barth ${ }^{3}$, Walajabad Sampath ${ }^{3}$, and Michael Walls ${ }^{1}$ \\ ${ }^{1}$ Loughborough University, Loughborough, Leicestershire, LE11 3TU, United Kingdom \\ ${ }^{2}$ Materials Department, Oxford University, Oxford, OX1 3PH, United Kingdom \\ ${ }^{3}$ Colorado State University, Fort Collins, Colorado, 80523, USA
}

\begin{abstract}
Impurity elements such as chlorine and sulphur can have significant effects on the electrical performance of cadmium telluride (CdTe) solar cells. Here, the 3D distribution of such elements in a cadmium chloride treated CdTe device has been determined by high resolution dynamic SIMS, a novel technique that has not been applied to thin-film PV cells. It is found that as well as segregating to grain boundaries following treatment, chlorine also segregates to the CdS/CdTe interface. Conversely, sulphur shows a U-shaped diffusion profile. These results have potential implications for the processing thin-film CdTe devices.
\end{abstract}

\section{INTRODUCTION}

It is well-known that an annealing treatment in the presence of cadmium chloride $\left(\mathrm{CdCl}_{2}\right)$ is necessary for the production of high efficiency CdTe solar cells. However, the treatment causes complex microstructural and chemical changes to the cell, including: CdTe recrystalisation and grain growth [1], the removal of stacking faults from CdTe grains [2], [3], CdTe grain boundary passivation with chlorine, and interdiffusion of sulphur and tellurium at the CdS/CdTe interface [1] (each of which has at one time or other been given as a reason for the positive effects of the $\mathrm{CdCl}_{2}$ treatment). Keeping track of the chemical effects of the treatment is therefore important in determining the optimal cell processing conditions for maximum efficiency. Here, the 3-dimensional distribution of elements in a $\mathrm{CdCl}_{2}$ treated device is determined by high resolution dynamic SIMS, a technique that has not been used before to characterise thin-film CdTe solar cells.

Two dimensional elemental characterisation of CdTe has been performed by Mao et al [4], who measured the planar distribution of chlorine and sulphur in a $\mathrm{CdCl}_{2}$ treated device by Time-of-Flight (ToF) SIMS. The 3D distribution of chlorine and sulphur in a substrate CdTe device has been measured by Kranz et al [5], also by ToF SIMS. Harvey et al performed 3D ToF SIMS in the absorber layer of a superstrate CdTe device [6]. The current technique combines the high resolution of ToF SIMS with the superior sensitivity of dynamic SIMS.

\begin{tabular}{|lr|}
\hline Back Contact \\
\hline CdTe & $2 \mu \mathrm{m}$ \\
\hline $\mathrm{CdS}$ & $120 \mathrm{~nm}$ \\
\hline $\mathrm{SnO}_{2} \cdot \mathrm{F}$ & $400 \mathrm{~nm}$ \\
\hline Glass & $3 \mathrm{~mm}$ \\
\hline
\end{tabular}

Fig. 1 Schematic of the superstrate CdTe device structure

\section{EXPERIMENTAL}

A plate of superstrate cadmium telluride (CdTe) devices was fabricated in an all-in-one vacuum process at Colorado State University [7]. In the process, $\sim 120 \mathrm{~nm}$ of cadmium sulphide (CdS) was sublimated onto an NSG Plikington, TEC12D glass substrate. This was followed by $\sim 2 \mu \mathrm{m}$ of $\mathrm{CdTe}$, resulting in a (glass/F: $\mathrm{SnO}_{2} / \mathrm{SnO}_{2} / \mathrm{CdS} / \mathrm{CdTe}$ ) device structure, as seen in figure 1 . The stack was then exposed to process of reference $\mathrm{CdCl}_{2}$ and $\mathrm{CuCl}$ treatments. The $\mathrm{CdCl}_{2}$ treatment lasted a total of 6 minutes, and was carried out in an atmosphere of nitrogen (with $2 \%$ oxygen). The stack was contacted with nickel-carbon paint, then sand-blasted to create 9 separate devices. These were JV tested, and a 12.01\% efficient device selected for further characterisation.

Following the removal of the back contact with acetone, the device was characterised with a Cameca NanoSIMS 50/50L Secondary Ion Mass Spectrometer (SIMS). Since the depth resolution of SIMS depth profiles are affected by initial surface topography, a region of the CdTe back surface was first polished in a dual beam SEM with a low current ion beam (polishing parallel to the substrate, with a beam current of $0.5 \mathrm{nA}$ ). In addition, a layer of platinum was deposited to help smooth the polishing of the surface, as is done in preparation of samples for Transmission Electron Microscopy. Mass spectrometry measurements were taken over a 5 x 5 micron beam raster area on the polished surface. This area was then ion eroded with a second ion beam, leaving the layer beneath, 
a)

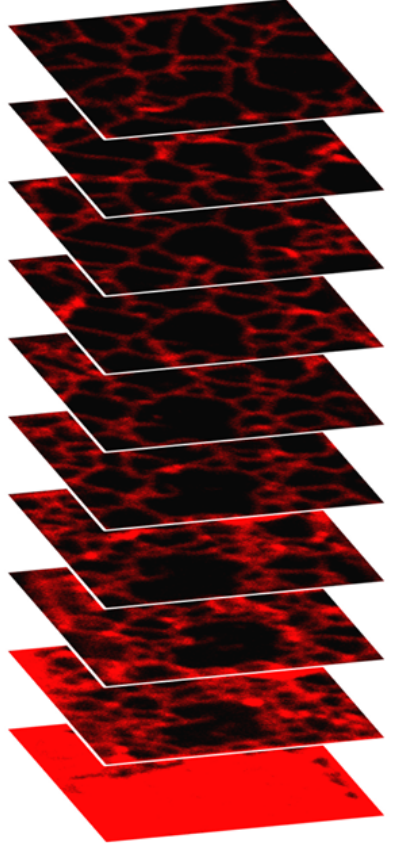

b)

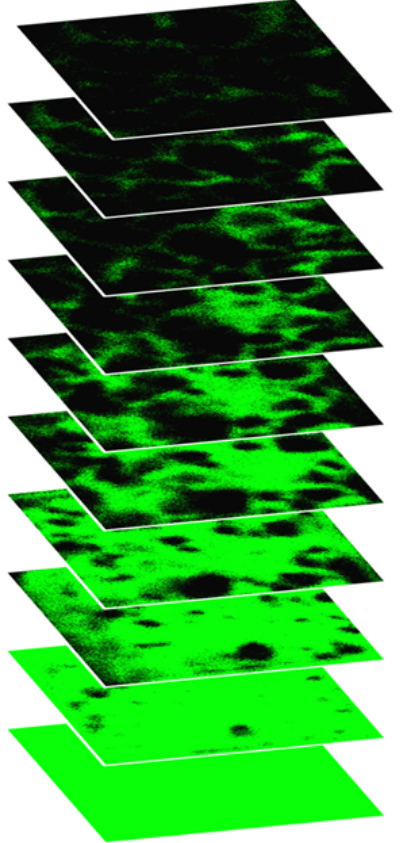

c)

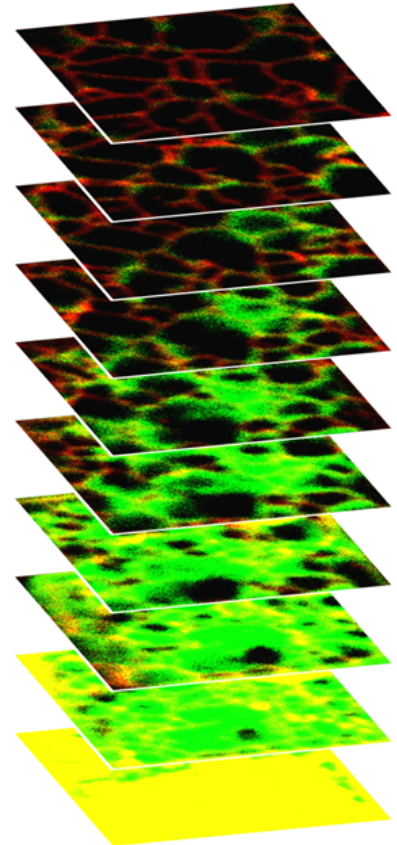

Fig. 2 Image stacks showing the distribution of a) chlorine and b) sulphur through the CdTe absorber, up to the CdS interface. Images in stacks a) and b) are combined to produce those in c) (with yellow indicating regions containing both chlorine and sulphur counts). The 10 images in each stack are planes $1,7,13,19,25,31,37,43,49$ and 55 . The field of view of each image is 5 x 5 microns.

around $10 \mathrm{~nm}$ below, to be measured. This process was then repeated through the depth of the cell. The spectrometer was tuned for $\mathrm{Cl}, \mathrm{S}$, Te, $\mathrm{Cu}$, and $\mathrm{F}$. Results for copper and fluorine are not included in the analysis.

\section{RESULTS}

The device chosen for elemental characterisation had a measured efficiency of $12.01 \%$, with a short-circuit current of $22.7 \mathrm{~mA} / \mathrm{cm}^{2}$, an open circuit voltage of $789 \mathrm{mV}$, and a fill factor of $67.1 \%$. These are in the range of typical values for CSU's basic, process of reference CdS cells. This indicates that there was nothing unusual with the deposition or processing of the measured cell.

NanoSIMS characterisation produced multiple stacks of 2D images, with each stack showing the distribution of a different element through the depth of the measured volume (one stack for each of the 5 elements). Chlorine, sulphur, and 'combined' stacks are shown in figure 2. Plotting the average number of counts per pixel in each image versus the plane number of that image produces a depth profile of the 1D distribution of the element through the cell. Each data point in a profile therefore corresponds to a 2D image for that element. This has been performed for Te, $\mathrm{S}$ and $\mathrm{Cl}$ in figure 3. As such, the $2 \mathrm{D}$ images shown in figures each correspond to a point on a profile in figure 3.

Chlorine - Figures 2, 3, 4 and 5 display the important features of the distribution of chlorine through the CdTe and CdS layers. Figure 2 a), showing the $\mathrm{Cl}$ distribution towards the back of the CdTe layer (plane number 3), clearly shows that chlorine is located mainly at the grain boundaries (GBs). Some bright spots corresponding to the highest chlorine counts can be seen at the confluence points of multiple GBs, and/or where the grain size - as seen from this plane - is small. There is no signal from the grain interiors (GIs).

These general patterns continue through the depth of the CdTe layer. Figure 3 shows a steady increase in average chlorine counts from planes 35 to 50 . This coincides with a decrease in apparent grain size closer to the CdS interface (and hence an increase in total GB length). This can be seen clearly in stack a) of figure 2 .

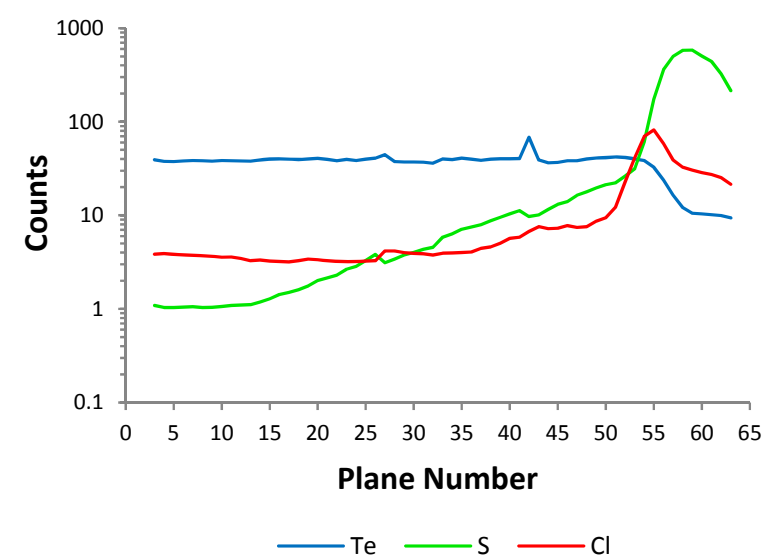

Fig. 3 1D profile of average chlorine, sulphur and tellurium counts through the CdTe and CdS layers. Plane number 1 is close to the back of the CdTe layer and plane number 65 is close to the transparent conductor 

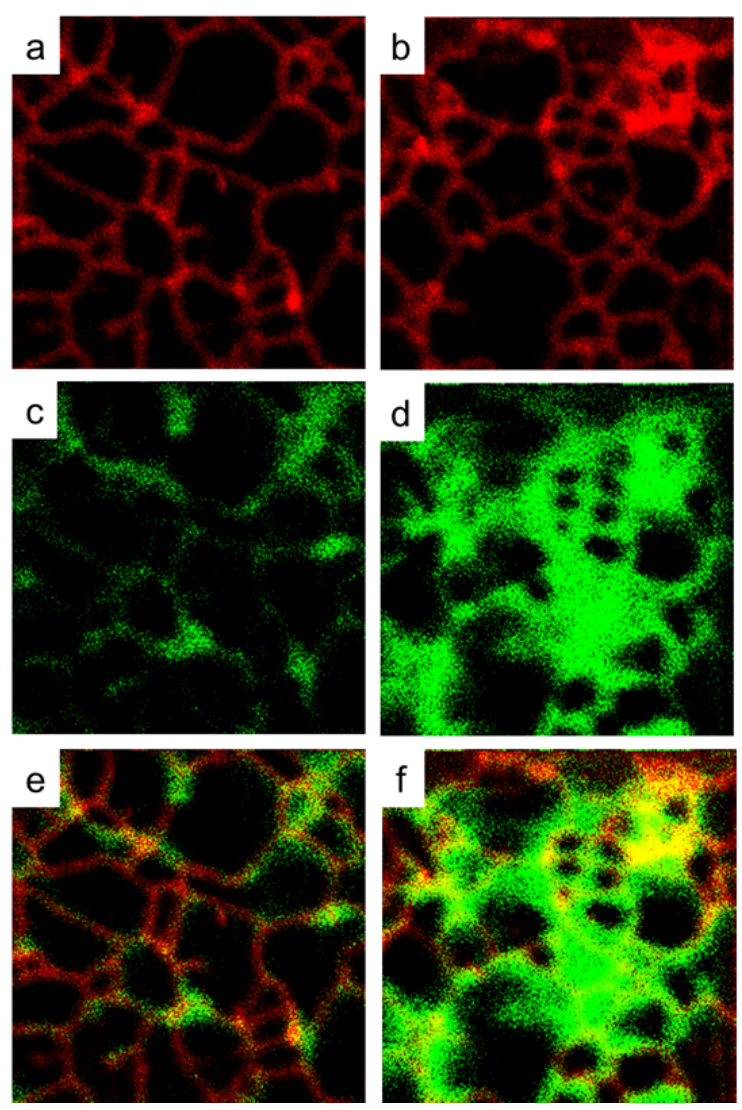

Fig. 4 NanoSIMS images of the chlorine (a \& b) and sulphur (c \& d) distributions in planes 3 and 26 of the image stack (LHS and RHS respectively). Images e) and $f$ ) are combinations of the $S$ and $\mathrm{Cl}$ images above. The grain structures in planes 3 and 26 do not align because of slight sample drift during the data acquisition. The field of view in each image is 5 x 5 microns.

Figure 1 also shows a sharp rise in average chlorine counts at the CdS/CdTe interface (the position of the interface is indicated by the spike in the $\mathrm{S}$ profile and drop in the Te profile at around plane 55). Although in 1D the chlorine concentrations appear very high in this region, it is not clear how much this is caused by geometry or change in matrix, rather than genuinely higher levels of $\mathrm{Cl}$ segregation at this
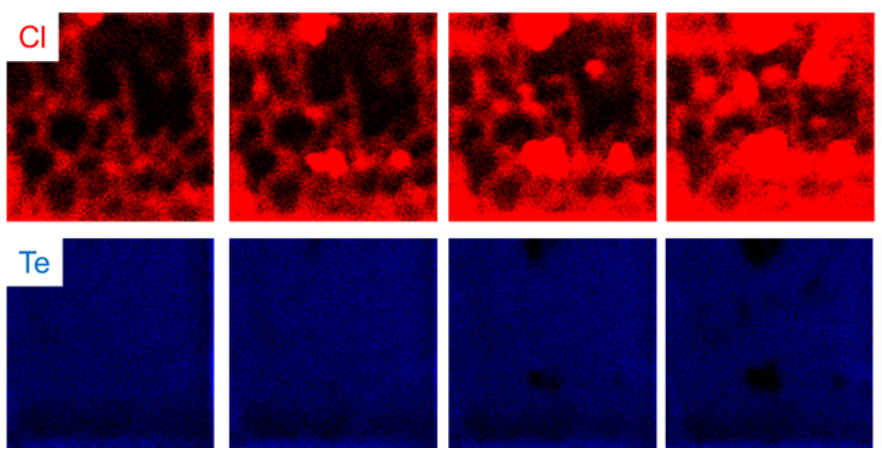

interface than at grain boundaries (i.e. the chlorine-containing interface is now parallel to or in the plane of the beam raster, meaning chlorine counts are collected over all areas of the image). This point is well illustrated in figure 3 . The images clearly show that chlorine is segregated along the CdS/CdTe interface. While the tellurium counts are reducing going from planes 50 to 57, indicating the end of the CdTe and beginning of the CdS, chlorine counts are increasing. Planes 56 and above in figures 3 and 5 both show high levels of chlorine counts in the CdS layer.

Sulphur - Figures 2, 3 and 4 display the important features of the distribution of sulphur through the CdTe and CdS layers. Figure $4 \mathrm{c}$ ), showing the $\mathrm{S}$ distribution towards the back of the CdTe layer, indicates some moderate $\mathrm{S}$ segregation at the grain boundaries. The GB segregation is qualitatively weaker than for chlorine in the same plane, as indicated by the combined image in part e) of the figure. Unlike with chlorine, average sulphur concentrations rise steadily from this point up until the CdS/CdTe interface. Figure $4 \mathrm{~d}$ ) shows that this is down to increased counts from the grain interiors, with sulphur signal now emanating from most areas but the middle of the larger grains. It should be noted that this is at the stage before apparent grain sizes have started to become significantly smaller, shown by the $\mathrm{Cl}$ in image 4 b).

\section{DISCUSSION}

The acquisition of high resolution elemental data in 3D allows predictions to be made in two key areas: 1 ) the kinetics of diffusing impurity species; and 2) what affect the species may be having on device performance. These can then be used to inform changes in device processing to improve performance.

It is clear from the data that chlorine strongly segregates to grain boundaries in CdTe. This is in agreement with other experiments [8]. The data also suggests that during treatment chlorine travels down the GBs to the CdS/CdTe interface, and continues into the CdS. While the segregation of chlorine at grain boundaries (and its pacifying effects) have been relatively well studied, chlorine segregation at the CdS interface has not. Chlorine has been seen at the interface in
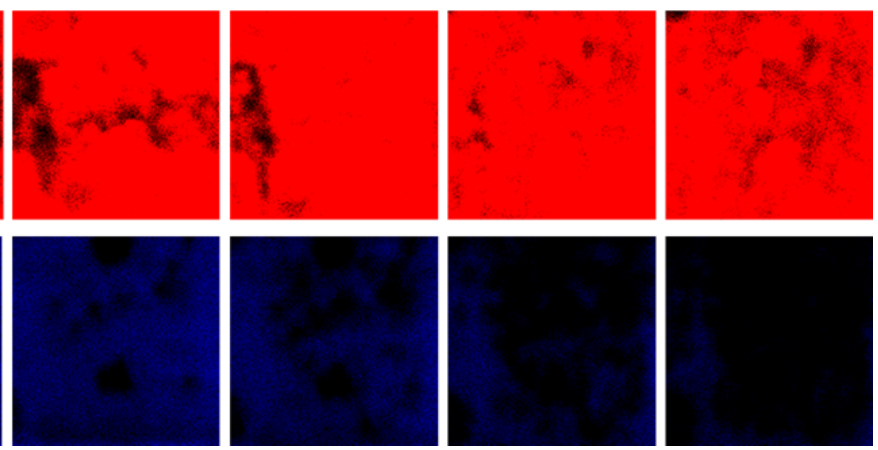

Fig. 5 Series of NanoSIMS images crossing the CdS/CdTe interface (planes 50 to 57, left to right). The top row shows chlorine and the bottom tellurium. The field of view in each image is $3.4 \times 3.4$ microns. 
cross-sectional TEM studies [8], [9] and an atom probe tomography study [10], but not in a plan-view series moving across the junction. The electrical effects of chlorine at the CdS/CdTe junction are not clear, but are likely to be significant given the key location at the p-n junction and the known electronic and band structure effects of chlorine in CdTe. It should also be noted that chlorine is likely to be present at the back surface of the CdTe, which is removed here in the process of polishing.

The series view of sulphur distribution through the CdTe showing progressively more $\mathrm{S}$ in the CdTe grain interiors as the CdS layer is approached - is consistent with a type B diffusion regime in the Harrison classification system [11]. This is where fringes of sulphur develop alongside grain boundaries due to out-diffusion from the boundaries, but do not overlap with one another [12]. The different diffusion regimes are shown in figure 6 in the appendix. The presence of sulphur in the CdTe layer - forming a CdTe ${ }_{1-x} S_{x}$ alloy - has potential microstructural and electrical effects. In terms of the microstructural effects, one theory is that the alloy reduces the C. $10 \%$ lattice mismatch between the two crystals, resulting in fewer misfit dislocations at the interface. Sulphur also decreases the band gap of CdTe due to band gap bowing.

\section{CONCLUSIONS}

High resolution 3D dynamic SIMS measurements have been carried out on a $\mathrm{CdCl}_{2}$ treated CdTe solar cell. Chlorine is observed to segregate strongly at grain boundaries and at the CdS/CdTe interface, and is present in the CdS layer. Sulphur shows weaker segregation to grain boundaries, and plan-view slices through the depth of the CdTe reveal a U-shaped diffusion profile within grains, suggesting a mixed grain boundary and lattice diffusion regime. These measurements give useful insights into the complex chemical effects of the $\mathrm{CdCl}_{2}$ annealing treatment, and are especially useful as through-thickness, plan-view images of this kind have rarely been employed in the chemical characterisation of CdTe. In future, the technique could be used to compare device sets with a range of different processing conditions and/or layer structures, and could include detailed studies of other elements such as copper, fluorine, sodium and oxygen.

\section{ACKNOWLEDGEMENTS}

One of the authors (TF) is grateful to the EPSRC SuperSolar Hub for funding an International Engagement secondment at Colorado State University.

\section{REFERENCES}

B. E. Mccandless, Ã. L. V Moulton, and R. W. Birkmire, "Recrystallization and Sulfur Di usion in CdCl 2 -Treated CdTe / CdS Thin Films,” vol. 5, no. March, pp. 249-260, 1997.
[2] A. Abbas, G. D. West, J. W. Bowers, P. Isherwood, P. M. Kaminski, B. Maniscalco, P. Rowley, J. M. Walls, K. Barricklow, W. S. Sampath, and K. L. Barth, "The effect of cadmium chloride treatment on close-spaced sublimated cadmium telluride thin-film solar cells," IEEE J. Photovoltaics, vol. 3, no. 4, pp. 1361-1366, 2013.

[3] T. Fiducia, A. Abbas, K. Barth, W. Sampath, and M. Walls, "Intragranular Defects in As-Deposited and Cadmium Chloride-Treated Polycrystalline Cadmium Telluride Solar Cells,” in 2016 IEEE 43rd Photovoltaic Specialist Conference (PVSC), 2016.

[4] D. Mao, G. Blatz, C. E. Wickersham, and M. Gloeckler, "Correlative impurity distribution analysis in cadmium telluride (CdTe) thin-film solar cells by ToF-SIMS 2D imaging," Sol. Energy Mater. Sol. Cells, vol. 157, pp. 6573, 2016.

[5] Lukas Kranz, Christina Gretener, Julian Perrenoud, Dominik Jaeger, Stephan S. A. Gerstl,Rafael Schmitt, Stephan Buecheler, and Ayodhya N. Tiwari “Tailoring Impurity Distribution in Polycrystalline CdTe Solar Cells for Enhanced Minority Carrier Lifetime,” Adv. Energy Mater., 2014.

[6] S. P. Harvey, G. Teeter, H. Moutinho, and M. M. Al-Jassim, "Direct evidence of enhanced chlorine segregation at grain boundaries in polycrystalline CdTe thin films via threedimensional TOF-SIMS imaging," Prog. Photovoltaics Res. Appl., vol. 23, no. 7, pp. 838-846, Jul. 2015.

[7] D. E. Swanson, J. M. Kephart, P. S. Kobyakov, K. Walters, K. C. Cameron, K. L. Barth, W. S. Sampath, J. Drayton, and J. R. Sites, "Single vacuum chamber with multiple close space sublimation sources to fabricate CdTe solar cells," $J$. Vac. Sci. Technol. A Vacuum, Surfaces, Film., vol. 34, no. 2, p. 021202, 2016.

[8] A. Abbas, D. Swanson, A. Munshi, K. L. Barth, W. S. Sampath, J. W. Bowers, P. M. Kaminski, and J. M. Walls, "The Effect of a Post-Activation Annealing Treatment on Thin Film CdTe Device Performance,” 2015.

[9] A. Abbas, G. . West, J. W. Bowers, P. M. Kaminski, B. Maniscalco, J. M. Walls, K. L. Barth, and W. S. Sampath, "Cadmium chloride assisted re-crystallization of CdTe: The effect of annealing over-treatment," in 2014 IEEE 40th Photovoltaic Specialist Conference (PVSC), 2014, pp. 0701-0706.

[10] J. D. Poplawsky, C. Li, N. R. Paudel, W. Guo, Y. Yan, and S. J. Pennycook, "Nanoscale doping profiles within CdTe grain boundaries and at the CdS/CdTe interface revealed by atom probe tomography and STEM EBIC,” Sol. Energy Mater. Sol. Cells, vol. 150, no. March, pp. 95-101, 2016.

[11] L. G. Harrison, "Influence of dislocations on diffusion kinetics in solids with particular reference to the alkali halides,” Trans. Faraday Soc., vol. 57, p. 1191, 1961.

[12] H. Mehrer, Diffusion in Solids. 2007. 
Type A

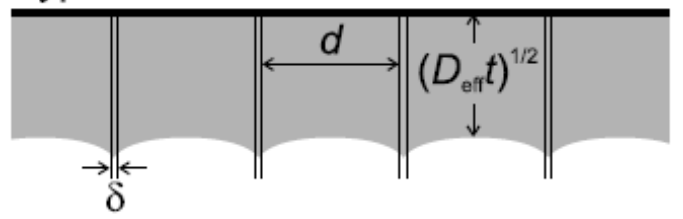

Type B

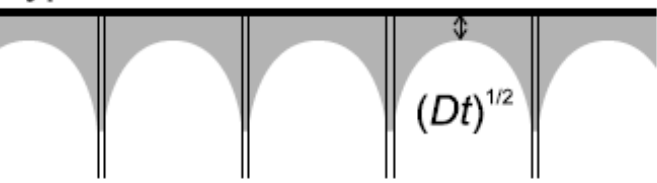

Type C

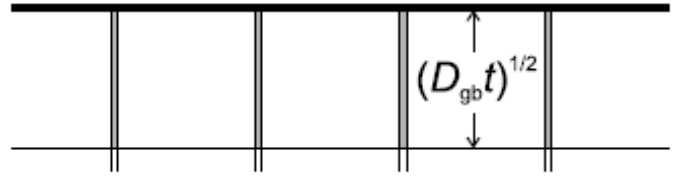

Fig. 6 Schematic of the type A, B, and C diffusion regimes [12] 